\title{
Efficacy and safety of underwater endoscopic mucosal resection for superficial non-ampullary duodenal epithelial tumors: Systematic review and meta-analysis
}

\author{
Neil Bhogala, Babu Mohan ${ }^{b}$, Saurabh Chandana ${ }^{a}$, Amaninder Dhaliwala, Suresh Ponnadac, Ishfaq Bhat ${ }^{a}$, \\ Shailender Singh ${ }^{\mathrm{a}}$, Douglas G. Adler ${ }^{\mathrm{d}}$ \\ University of Nebraska Medical Center, Omaha NE; University of Arizona, Tucson, AZ; Carilion Clinic, Roanoke, VA; \\ University of Utah School of Medicine, Salt Lake City, UT, USA
}

\section{Abstract}

\begin{abstract}
Background Superficial non-ampullary duodenal epithelial tumors (SNADET) are increasingly found during upper endoscopy. Underwater endoscopic mucosal resection (UEMR) is an emerging technique for the endoscopic resection of SNADET. We performed a systematic review and meta-analysis to evaluate the efficacy and safety of this technique.
\end{abstract}

Methods We conducted a comprehensive search of several databases from inception to August 2019, which included Ovid Cochrane Database of Systematic Reviews, Ovid Embase, Scopus, Ovid Cochrane Central Register of Controlled trials, Ovid MEDLINE ${ }^{\circledR}$, and In-Process and other nonindexed citations. The primary outcome assessed was the pooled clinical success rate of UEMR. Secondary outcomes included rate of en bloc resection, pooled rate of high-grade dysplasia or intramucosal carcinoma (HGIC), and pooled rate of adverse events. Meta-regression analysis was performed based on tumor size.

Results A total of 8 study arms were included for analysis with UEMR performed in a total of 258 lesions. The pooled clinical success rate was $89.9 \%$ (95\% confidence interval [CI] 83.4-94.1). Enbloc removal was achieved in $84.6 \%$ of treated lesions (95\% CI 75.5-90.7). The pooled rate of HGIC was $24.7 \%$ (95\%CI 10.3-48.3). The pooled rate of adverse events was $6.9 \%$ (95\%CI $2.5-17.9)$. This included 10 total adverse events, with the majority being self-limited delayed bleeding. There were no duodenal perforations.

Conclusions UEMR for endoscopic resection of SNADET has a high efficacy. In addition, this technique has a high rate of en bloc resection and an acceptable adverse event profile. Given these data, UEMR should be considered as a method for endoscopic resection of SNADET.

Keywords Duodenum, non-ampullary adenoma, underwater endoscopic mucosal resection

Ann Gastroenterol 2020; 33 (4): 1-13
Division of ${ }^{a}$ Gastroenterology and Hepatology, University of Nebraska Medical Center, Omaha NE (Neil Bhogal, Saurabh Chandan, Amaninder Dhaliwal, Ishfaq Bhat, Shailender Singh); 'Internal Medicine, University of Arizona, Tucson AZ (Babu Mohan); 'Internal Medicine, Carilion Clinic, Roanoke VA (Suresh Ponnada); ${ }^{\mathrm{d}}$ Gastroenterology and Hepatology, University of Utah School of Medicine, Salt Lake City UT (Douglas G. Adler), USA

Conflict of Interest: None

Correspondence to: Douglas G. Adler MD, FACG, AGAF, FASGE, Professor of Medicine, Director of Therapeutic Endoscopy, Director, GI Fellowship Program, Gastroenterology and Hepatology, University of Utah School of Medicine, Salt Lake City, UT, 84132, USA, e-mail: Douglas.adler@hsc.utah.edu

Received 11 February 2020; accepted 21 April 2020; published online 30 May 2020

DOI: https://doi.org/10.20524/aog.2020.0504

\section{Introduction}

Superficial non-ampullary duodenal epithelial tumors (SNADET) are uncommonly encountered during upper endoscopy as opposed to ampullary tumors [1]. However, the incidence of non-ampullary adenomas and duodenal adenocarcinoma is increasing. A multicenter study conducted in Japan from 2007-2012 showed 396 SNADET resected lesions in 364 patients [2]. The incidence increased 2 -fold over the study duration (from first to second half) and the incidence of duodenal adenocarcinoma increased 3-fold.

There is no standardized technique for endoscopic resection of SNADET. Endoscopic mucosal resection (EMR) with submucosal injection and endoscopic submucosal dissection (ESD) are commonly utilized. EMR has been shown to have a superior safety profile; however, this technique has 
the disadvantage of lower rates of complete initial resection, requiring multiple endoscopy sessions, and a recurrence rate of up to $37 \%$ [3]. In contrast, ESD has been shown to be superior regarding the rate of complete resection. However, ESD has limited experience in western countries and is associated with higher rates of perforation [4].

Underwater EMR (UEMR) is an emerging technique for endoscopic resection. This technique was first described by Binmoeller et al for mucosal resection of large colonic polyps [5]. UEMR for colonic polyps has been shown to be superior to traditional EMR with submucosal injection in terms of macroscopic resection and local recurrence [6]. In addition, subsequent studies have shown that UEMR has low rates of adverse events and self-limited delayed bleeding [7]. UEMR has been more recently described for the endoscopic resection of SNADET. The purpose of our study was to perform a systematic review and meta-analysis of the available literature to evaluate the efficacy and safety of UEMR for SNADET.

\section{Materials and methods}

\section{Search strategy}

We conducted a comprehensive search of several databases from inception to August 2019. An experienced medical librarian assisted with the literature search. The databases searched were as follows: Ovid Cochrane Database of Systematic Reviews, Ovid Embase, Scopus, Ovid Cochrane Central Register of Controlled trials, Ovid MEDLINE ${ }^{\circledR}$, and In-Process and other non-indexed citations. Controlled vocabulary supplemented with keywords was used to search for studies of interest. The full search strategy is available in Appendix1. The PRISMA and MOOSE checklists were followed and are provided in Appendices 2 and $3[8,9]$.

\section{Study selection}

In this meta-analysis, we included studies that evaluated the clinical outcomes of UEMR. Studies were included regardless of sample size, study setting or location, as long as the data needed for the analysis were available.

Our exclusion criteria were studies that had pediatric patients (age $<18$ years old) and studies not published in the English language. If there were multiple publications from the same cohort and/or overlapping cohorts, data from the most recent and/or most appropriate comprehensive report were retained.

\section{Data abstraction and quality assessment}

Outcomes data from each study were abstracted onto a standardized form by a minimum of 2 authors, and 2 authors independently completed quality scoring. The NewcastleOttawa scale for cohort studies was used to assess the quality of studies [10]. The details of this scoring system can be found in Supplementary Table 1.

\section{Outcomes assessed}

1. Pooled rate of clinical success

2. Pooled rate of en bloc tumor removal

3. Pooled rate of high-grade dysplasia/intramucosal carcinoma (HGIC)

4. Pooled rate of adverse events

Meta-regression analysis based on the tumor size was also performed. Clinical success was defined in 7 studies as complete endoscopic resection without local recurrence on follow-up examination. A single study defined clinical success as complete endoscopic resection and did not have follow up.

\section{Statistical analysis}

The meta-analysis was carried out by calculating the pooled estimates following the methods suggested by DerSimonian and Laird. The random-effects model was used [11]. When the incidence of an outcome was zero in a study, a continuity correction of 0.5 was added to the number of incident cases before statistical analysis [12]. Heterogeneity was assessed by using the Cochran Q statistical test for heterogeneity, 95\% prediction interval (PI) [13-15], and the $I^{2}$ statistics [16,17]. In the latter, values of $<30 \%, 30-60 \%, 61-75 \%$ and $>75 \%$ were considered to be of low, moderate, substantial and considerable heterogeneity, respectively [18]. Publication bias was ascertained qualitatively, by visual inspection of a funnel plot, and quantitatively, by the Egger test [19-21]. A P value of $<0.05$ was used a priori to define significance of differences between groups, as provided by the statistical software. All analyses were performed using Comprehensive Meta-Analysis (CMA) software, version 3 (BioStat, Englewood, NJ).

\section{Results}

\section{Search results and population characteristics}

From an initial 69 studies, 33 records were screened and 25 full-length articles were assessed. Eight studies were included in the final analysis [22-29]. A schematic diagram of the study selection is provided in Supplementary Fig. 1 and the population characteristics are described in Table 1.

\section{Characteristics and quality of included studies}

There were no multicenter or population based studies. Two studies had sample sizes $>40$. The detailed assessment is 


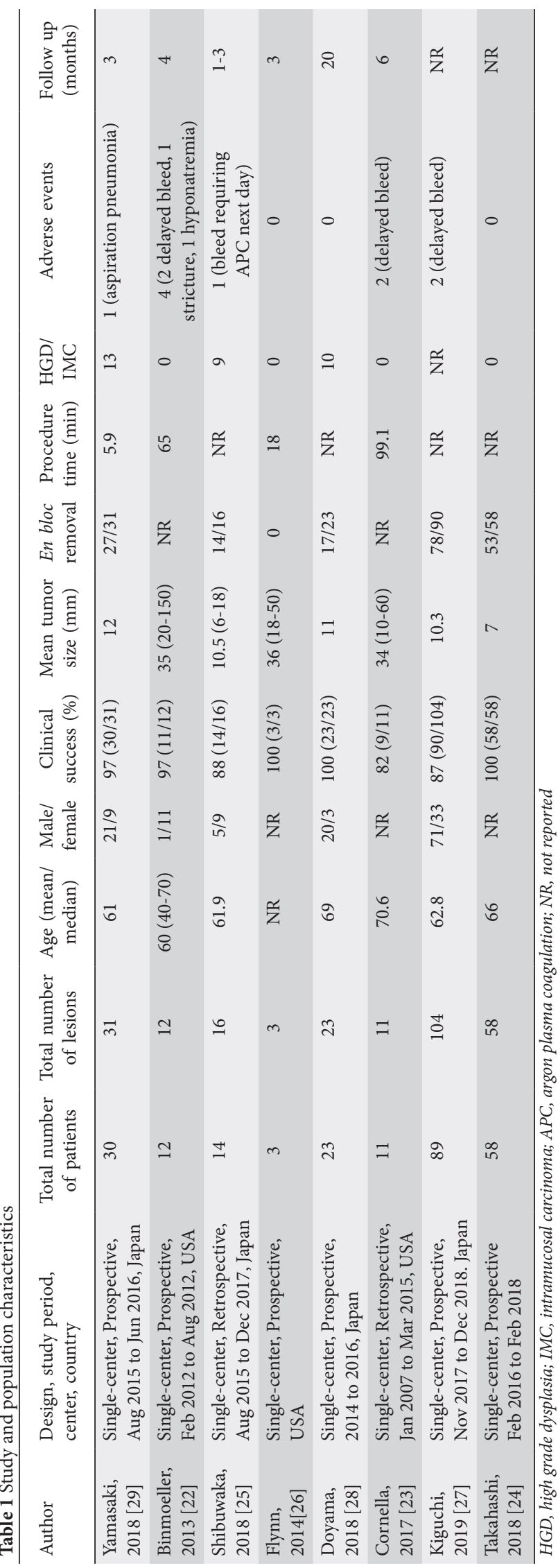

summarized in Supplementary Table 1. Overall, 7 studies were considered to be of medium-quality and one study of highquality. There were no low-quality studies.

\section{Meta-analysis outcomes}

\section{Demographics and clinical success}

There were 258 SNADET resected using the UEMR technique in 240 patients. The median patient age was 64.5 years. The mean tumor size was $19.4 \mathrm{~mm}$ (6-150).

Clinical success was reported in 8 studies that evaluated 240 patients. The pooled clinical success rate was $89.9 \%$ (95\%CI 83.4-94.1). The $I^{2}$ heterogeneity was $13 \%$ with a $95 \%$ PI of 76-96.

En bloc removal was reported in 6 studies that evaluated 221 patients and the achieved pooled rate was $84.6 \%$ of treated lesions (95\%CI 75.5-90.7), with an $I^{2}$ heterogeneity of $44 \%$ and 95\% PI of 55-96. HGIC lesions reported in 7 studies, evaluated 151 patients. The pooled rate of HGIC lesions was $24.7 \%$ (95\%CI 10.3-48.3), with an $I^{2}$ heterogeneity of 70\% and 95\% PI of 2-87.

\section{Adverse events}

Adverse events were reported in 8 studies that evaluated 240 patients. The pooled rate of adverse events was $6.9 \%$ (95\%CI 2.5-17.9), with an $I^{2}$ heterogeneity of $60 \%$ and $95 \%$ PI $1-63$. This included 10 total adverse events, of which 9 were postoperative. There were no documented duodenal perforations. There were 7 patients with delayed bleeding. Of these patients, 6 were managed conservatively and 1 patient required endoscopic therapy. Other adverse outcomes included 1 patient with aspiration, 1 patient with postprocedural hyponatremia, and 1 patient who developed a duodenal stricture.

\section{Analysis based on tumor size}

A meta-regression analysis was performed based on tumor size and the result was not significant, with a 2-sided $\mathrm{P}$ value of 0.47 . This was performed to assess if there was any difference in clinical success based on tumor size, and no significant difference was found. The pooled results are summarized in Table 2 and Supplementary Fig. 2-5.

\section{Validation of meta-analysis results}

\section{Sensitivity analysis}

We excluded each study, one at a time, and analyzed the effect on the main summary estimate. This was to assess whether any single study had a dominant effect on the metaanalysis outcome results. In this analysis, no single study significantly affected the outcome or the heterogeneity. This was performed for all outcomes. 
Table 2 Summary of pooled results

\begin{tabular}{lc}
\hline Outcomes & Pooled rate $\left(95 \% \mathrm{CI}, I^{2}\right)$ \\
\hline Clinical success (8 studies, 240 patients) & $\begin{array}{c}89.9 \%(83.4-94.1,13) \\
\text { (PI: 76-96) }\end{array}$ \\
\hline En bloc removal (6 studies, 221 patients) & $\begin{array}{c}84.6 \%(75.5-90.7,44) \\
\text { (PI: 55-96) }\end{array}$ \\
$\begin{array}{l}\text { HGD/Intramucosal Ca (7 studies, } 151 \\
\text { patients) }\end{array}$ & $\begin{array}{c}24.7 \%(10.3-48.3,70) \\
\text { (PI: } 2-87)\end{array}$ \\
Adverse events (8 studies, 240 patients) & $6.9 \%(2.5-17.9,60)$ \\
Meta-regression based on tumor size & (PI: $1-63)$ \\
$\begin{array}{l}\text { Publication bias, Eggers 2-tailed } \\
\text { P-value=0.07 }\end{array}$ & \\
\hline $\begin{array}{l}\text { HGD, high-grade dysplasia; } \text { Ca, carcinoma; } \text { CI, confidence interval; } \text { PI, } \\
\text { prediction interval }\end{array}$ &
\end{tabular}

\section{Heterogeneity}

We assessed the dispersion of the calculated rates using the PI and $I^{2}$ percentage values. The PI gives an idea of the range of the dispersion and $I^{2}$ tell us what proportion of the dispersion is true vs. chance [15]. The calculated PIs are reported with the pooled results in Table 2. The PI was narrow with minimal heterogeneity in the pooled clinical success rate.

\section{Publication bias}

Publication bias assessment was carried out in relation to the primary outcomes in hand, which were the pooled rate of clinical success and pooled rate of en bloc removal. Based on visual inspection of the funnel plot, as well as quantitative measurement using the Egger regression test, there was no evidence of publication bias (Supplementary Fig. 6, Eggers 2-tailed $\mathrm{P}=0.07,0.6)$.

\section{Quality of evidence}

The GRADE working group approach was used to assess the quality of evidence [30]. Observational studies start with a low-quality rating. This meta-analysis would be considered low quality of evidence, based on factors such as publication bias, heterogeneity, risk of bias and indirectness. These results are summarized in Table 3.

\section{Discussion}

In this study we present a systematic review and metaanalysis of the efficacy and safety of UEMR for SNADET. The pooled clinical success rate was $89.9 \%$ and the adverse event rate was $6.9 \%$. The adverse events were generally self-limited, with no documented perforations. In addition, the en bloc
Table 3 Summary of findings, quality of evidence

\begin{tabular}{lll}
\hline Outcomes & $\begin{array}{l}\text { Number of studies / } \\
\text { patients }\end{array}$ & $\begin{array}{l}\text { Quality of evidence } \\
\text { (GRADE) }\end{array}$ \\
\hline Clinical success & 8 studies, 240 patients & Low \\
\hline En bloc removal & 6 studies, 221 patients & Low \\
HGD/ & 7 studies, 151 patients & Low \\
Intramucusal Ca & & \\
Adverse events & 8 studies, 240 patients & Low \\
\hline
\end{tabular}

HGD, high-grade dysplasia; $\mathrm{Ca}$, carcinoma

resection rate was high at $84.6 \%$. Meta-regression analysis showed no significant difference in clinical success based on tumor size. Based on these results, this technique appears to be a safe and effective method for endoscopic resection in the duodenum.

UEMR is an emerging technique for resection of superficial epithelial tumors in the gastrointestinal tract. The efficacy and safety of this technique is well described for resection of colonic polyps. In a recent systematic review and metaanalysis of UEMR for colorectal lesions, complete resection was achieved in $96.4 \%$ of lesions and the adverse event rate was low at $3.3 \%$. As in our analysis, no cases of perforation, a feared complication of both EMR and ESD, were reported [31].

Several factors make complete endoscopic resection of mucosal lesions difficult in the duodenum. These include a relatively narrow lumen, occasional luminal angulation, glandular formation precluding adequate submucosal lifting, and a thin muscular wall, which may increase the risk of perforation [32]. The most commonly described technique is traditional EMR with submucosal injection. A recent systematic review of 10 studies showed a $93 \%$ rate of complete resection using traditional EMR. However, this technique was also associated with a pooled bleeding rate of $16 \%$, a perforation rate of $1 \%$ and a recurrence rate of $15 \%$ [33]. There was a delayed bleeding rate of $5 \%$ requiring endoscopic therapy, with one patient requiring surgical intervention.

Although less well studied, ESD is also a commonly utilized technique for the treatment of SNADET. This procedure is associated with less procedural bleeding than EMR; however, it carries a high perforation rate of $6-50 \%$, limiting its utility in this setting [34-36]. In addition, this technique is not frequently employed in western countries, thus limiting its generalizability.

UEMR for SNADET has thus far shown promise. The pooled clinical success rate is comparable to both EMR and ESD. In addition, the adverse event profile appears acceptable, with no documented duodenal perforations and relatively benign post-procedural bleeding in previous studies.

There are several strengths to this study. There were no low-quality studies included. In addition, there was minimal heterogeneity and no publication bias found. However, the study also has limitations. Given the novelty of UEMR for SNADET, only 8 studies were included for analysis. In addition, all of the studies were single-center observational studies, although the majority were prospective. There was also a wide range in the mean size of tumor resection (6-150 mm). Finally, 
2 studies did not report on rate of en bloc resection, 1 study did not report on HGIC, and 1 study did not report follow-up endoscopic examinations. Regardless, there is a relative paucity of data regarding endoscopic resection of SNADET and this study supports using UEMR in this setting.

In conclusion, UEMR appears to be an effective technique for SNADET. In addition, the adverse event profile is acceptable, with no documented duodenal perforation. Based on these results, this technique should be considered as a therapeutic option for resection of SNADET.

\section{Acknowledgments}

We would like to acknowledge Emily Glenn in the McGoogan Library at the University of Nebraska, School of Medicine for providing assistance with a literature review. We would also like to acknowledge Kenneth Binmoeller, MD, at California Pacific Medical Center, for pioneering the technique of UEMR.

\section{Summary Box}

\section{What is already known:}

- The incidence of superficial non-ampullary duodenal epithelial tumors (SNADET) is increasing

- Commonly used techniques for endoscopic removal including traditional endoscopic mucosal resection (EMR) and endoscopic submucosal dissection both have limitations in this setting

- Underwater EMR (UEMR) is an emerging technique for endoscopic resection; previous studies involving the colorectum have shown excellent efficacy and safety

\section{What the new findings are:}

- UEMR has high pooled rates of clinical success and en bloc removal for SNADET

- UEMR has an acceptable pooled rate of adverse events, with no documented duodenal perforations

- UEMR is an effective technique for endoscopic removal of SNADET

\section{References}

1. Ochiai Y, Kato M, Kiguchi Y, et al. Current status and challenges of endoscopic treatments for duodenal tumors. Digestion 2019;99:21-26.

2. Goda K, Kikuchi D, Yamamoto Y, et al. Endoscopic diagnosis of superficial non-ampullary duodenal epithelial tumors in Japan: multicenter case series. Dig Endosc 2014;26 Suppl 2:23-29.

3. Kakushima N, Kanemoto H, Tanaka M, Takizawa K, Ono H. Treatment for superficial non-ampullary duodenal epithelial tumors. World J Gastroenterol 2014;20:12501-12508.

4. Hoteya S, Furuhata T, Takahito T, et al. Endoscopic submucosal dissection and endoscopic mucosal resection for non-ampullary superficial duodenal tumor. Digestion 2017;95:36-42.

5. Binmoeller KF, Weilert F, Shah J, Bhat Y, Kane S. "Underwater" EMR without submucosal injection for large sessile colorectal polyps (with video). Gastrointest Endosc 2012;75:1086-1091.

6. Schenck RJ, Jahann DA, Patrie JT, et al. Underwater endoscopic mucosal resection is associated with fewer recurrences and earlier curative resections compared to conventional endoscopic mucosal resection for large colorectal polyps. Surg Endosc 2017;31:4174-4183.

7. Uedo N, Nemeth A, Johansson GW, Toth E, Thorlacius H. Underwater endoscopic mucosal resection of large colorectal lesions. Endoscopy 2015;47:172-174.

8. Moher D, Liberati A, Tetzlaff J, Altman DG; PRISMA Group. Preferred reporting items for systematic reviews and metaanalyses: the PRISMA statement. Ann Intern Med 2009;151:264269, W64.

9. Stroup DF, Berlin JA, Morton SC, et al. Meta-analysis of observational studies in epidemiology: a proposal for reporting. Meta-analysis Of Observational Studies in Epidemiology (MOOSE) group. JAMA 2000;283:2008-2012.

10. Stang A. Critical evaluation of the Newcastle-Ottawa scale for the assessment of the quality of nonrandomized studies in metaanalyses. Eur J Epidemiol 2010;25:603-605.

11. DerSimonian R, Laird N. Meta-analysis in clinical trials. Control Clin Trials 1986;7:177-188.

12. Sutton AJ, Abrams KR, Jones DR, et al. Methods for meta-analysis in medical research. New York: John Wiley \& Sons Ltd.; 2000, pp. 205-28.

13. Higgins J, Thompson SG, Spiegelhalter DJ. A re-evaluation of random-effects meta-analysis. J R Stat Soc Ser A Stat Soc 2009;172:137-159.

14. Riley RD, Higgins JP, Deeks JJ. Interpretation of random effects meta-analyses. BMJ 2011;342:d549.

15. Mohan BP, Adler DG. Heterogeneity in systematic review and meta-analysis: how to read between the numbers. Gastrointest Endosc 2019;89:902-903.

16. Kanwal F, White D. "Systematic reviews and meta-analyses" in Clinical Gastroenterology and Hepatology. Clin Gastroenterol Hepatol 2012;10:1184-1186.

17. Higgins JP, Thompson SG, Deeks JJ, Altman DG. Measuring inconsistency in meta-analyses. BMJ 2003;327:557-560.

18. Guyatt GH, Oxman AD, Kunz R, et al. GRADE guidelines: 7. Rating the quality of evidence-inconsistency. J Clin Epidemiol 2011;64:1294-1302.

19. Easterbrook PJ, Berlin JA, Gopalan R, Matthews DR. Publication bias in clinical research. Lancet 1991;337:867-872.

20. Duval S, Tweedie R. Trim and fill: A simple funnel-plot-based method of testing and adjusting for publication bias in metaanalysis. Biometrics 2000;56:455-463.

21. Rothstein HR, Sutton AJ, Borenstein M. Publication bias in metaanalysis: Prevention, assessment and adjustments. John Wiley and Sons, 2006.

22. Binmoeller KF, Shah JN, Bhat YM, Kane SD. "Underwater" EMR of sporadic laterally spreading nonampullary duodenal adenomas (with video). Gastrointest Endosc 2013;78:496-502.

23. Cornella S, Flynn MM, Strand D, et al. Underwater endoscopic mucosal resection (EMR) appears safe and efficacious compared to conventional EMR for the removal of duodenal adenomas. Gastrointest Endosc 2017;85:AB298.

24. Takahashi A, Oyama T. Usefulness of underwater EMR for 
nonampullary duodenal tumor. United European Gastroenterol J 2018;6:A723-A724.

25. Shibukawa G, Irisawa A, Sato A, et al. Endoscopic mucosal resection performed underwater for nonampullary duodenal epithelial tumor: Evaluation of feasibility and safety. Gastroenterol Res Pract 2018;2018:7490961.

26. Flynn MM, Wang AY. Underwater endoscopic mucosal resection of large duodenal adenomas (Video). VJGIEN 2014;2:84-86.

27. Kiguchi $Y$, Kato M, Nakayama A, et al. Feasibility study comparing underwater endoscopic mucosal resection and conventional endoscopic mucosal resection for superficial non-ampullary duodenal epithelial tumor $<20 \mathrm{~mm}$. Dig Endosc 2019 Sep 9 [Epub ahead of print]. doi: 10.1111/den.13524

28. Doyama H, Tsuji S, Miyajima S, et al. Clinical outcomes of underwater endoscopic mucosal resection for superficial nonampullary duodenal epithelial tumors. J Gastroenterol Hepatol 2018;33:122.

29. Yamasaki Y, Uedo N, Takeuchi Y, et al. Underwater endoscopic mucosal resection for superficial nonampullary duodenal adenomas. Endoscopy 2018;50:154-158.

30. Puhan MA, Schünemann HJ, Murad MH, et al; GRADE Working
Group. A GRADE Working Group approach for rating the quality of treatment effect estimates from network meta-analysis. BMJ 2014;349:g5630.

31. Spadaccini M, Fuccio L, Lamonaca L, et al. Underwater EMR for colorectal lesions: a systematic review with meta-analysis (with video). Gastrointest Endosc 2019;89:1109-1116.e4.

32. Gaspar JP, Stelow EB, Wang AY. Approach to the endoscopic resection of duodenal lesions. World J Gastroenterol 2016;22:600-617.

33. Navaneethan U, Hasan MK, Lourdusamy V, Zhu X, Hawes RH, Varadarajulu S. Efficacy and safety of endoscopic mucosal resection of non-ampullary duodenal polyps: a systematic review. Endosc Int Open 2016;4:E699-E708.

34. Shibagaki K, Ishimura N, Kinoshita Y. Endoscopic submucosal dissection for duodenal tumors. Annals Transl Med 2017;5:188.

35. Jung JH, Choi KD, Ahn JY, et al. Endoscopic submucosal dissection for sessile, nonampullary duodenal adenomas. Endoscopy 2013;45:133-135.

36. Lim CH, Cho YS. Nonampullary duodenal adenoma: Current understanding of its diagnosis, pathogenesis, and clinical management. World J Gastroenterol 2016;22:853-861. 


\section{Supplementary material}

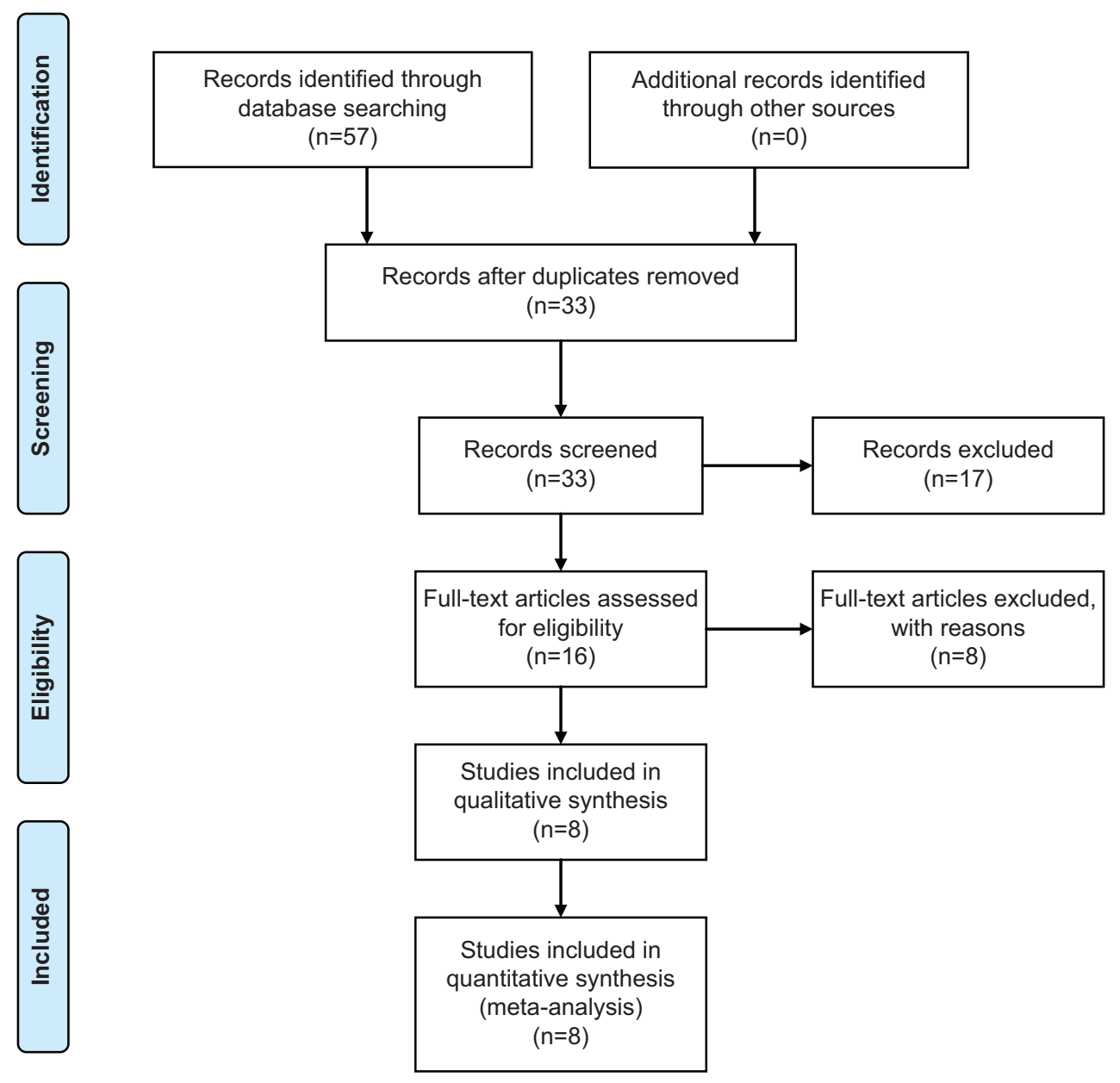

Supplementary Figure 1 Study flow selection

\begin{tabular}{|c|c|c|c|c|c|c|c|c|c|}
\hline \multirow[t]{2}{*}{ Study name } & \multicolumn{4}{|c|}{ Statistics for each study } & \multicolumn{5}{|c|}{ Event rate and $95 \% \mathrm{Cl}$} \\
\hline & $\begin{array}{c}\text { Event } \\
\text { rate }\end{array}$ & $\begin{array}{r}\text { Lower } \\
\text { limit }\end{array}$ & $\begin{array}{l}\text { Upper } \\
\text { limit }\end{array}$ & p-Value & & & & & \\
\hline Yamasaki, 2018 & 0.968 & 0.804 & 0.995 & 0.001 & & & & & $\Rightarrow$ \\
\hline Binmoeller, 2013 & 0.917 & 0.587 & 0.988 & 0.022 & & & & & - \\
\hline Shibuwaka, 2018 & 0.875 & 0.614 & 0.969 & 0.010 & & & & & \\
\hline Flynn, 2014 & 0.875 & 0.266 & 0.993 & 0.198 & & & & & \\
\hline Doyama, 2018 & 0.979 & 0.741 & 0.999 & 0.007 & & & & & $\rightarrow$ \\
\hline Comella, 2017 & 0.818 & 0.493 & 0.954 & 0.054 & & & & & - \\
\hline Kiguchi, 2019 & 0.865 & 0.785 & 0.919 & 0.000 & & & & & \\
\hline \multirow[t]{3}{*}{ Takahashi, 2018} & 0.992 & 0.879 & 0.999 & 0.001 & & & & & $\rightarrow$ \\
\hline & 0.899 & 0.834 & 0.941 & 0.000 & | & 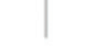 & | & & $\boldsymbol{\nabla}$ \\
\hline & & & & & -1.00 & -0.50 & 0.00 & 0.50 & 1.00 \\
\hline
\end{tabular}

Supplementary Figure 2 Forest plot, clinical success 


\begin{tabular}{|c|c|c|c|c|c|c|c|c|c|}
\hline \multirow[t]{2}{*}{ Study name } & \multicolumn{4}{|c|}{ Statistics for each study } & & \multicolumn{3}{|c|}{ Event rate and $95 \% \mathrm{Cl}$} & \\
\hline & $\begin{array}{r}\text { Event } \\
\text { rate }\end{array}$ & $\begin{array}{r}\text { Lower } \\
\text { limit }\end{array}$ & $\begin{array}{r}\text { Upper } \\
\text { limit }\end{array}$ & p-Value & & & & & \\
\hline Yamasaki, 2018 & 0.871 & 0.703 & 0.951 & 0.000 & & & & & \\
\hline Shibuwaka, 2018 & 0.875 & 0.614 & 0.969 & 0.010 & & & & & \\
\hline Flynn, 2014 & 0.167 & 0.010 & 0.806 & 0.299 & & & & & \\
\hline Doyama, 2018 & 0.739 & 0.528 & 0.878 & 0.028 & & & & & \\
\hline Kiguchi, 2019 & 0.867 & 0.780 & 0.923 & 0.000 & & & & & \\
\hline \multirow[t]{3}{*}{ Takahashi, 2018} & 0.914 & 0.809 & 0.964 & 0.000 & & & & & \\
\hline & 0.846 & 0.755 & 0.907 & 0.000 & & & & & \\
\hline & & & & & -1.00 & -0.50 & 0.00 & 0.50 & 1.00 \\
\hline
\end{tabular}

Supplementary Figure 3 Forest plot, en bloc removal

\begin{tabular}{|c|c|c|c|c|c|c|c|}
\hline \multirow[t]{2}{*}{ Study name } & \multicolumn{4}{|c|}{ Statistics for each study } & & \multicolumn{2}{|l|}{ Event rate and $95 \% \mathrm{Cl}$} \\
\hline & $\begin{array}{c}\text { Event } \\
\text { rate }\end{array}$ & $\begin{array}{r}\text { Lower } \\
\text { limit }\end{array}$ & $\begin{array}{l}\text { Upper } \\
\text { limit }\end{array}$ & $p$-Value & & & \\
\hline Yamasaki, 2018 & 0.433 & 0.271 & 0.612 & 0.467 & & & \\
\hline Binmoeller, 2013 & 0.042 & 0.003 & 0.425 & 0.030 & & & \\
\hline Shibuwaka, 2018 & 0.643 & 0.376 & 0.843 & 0.292 & & & \\
\hline Flynn, 2014 & 0.167 & 0.010 & 0.806 & 0.299 & & & \\
\hline Doyama, 2018 & 0.435 & 0.252 & 0.637 & 0.533 & & & \\
\hline Comella, 2017 & 0.045 & 0.003 & 0.448 & 0.035 & & & \\
\hline \multirow[t]{3}{*}{ Takahashi, 2018} & 0.009 & 0.001 & 0.123 & 0.001 & & & \\
\hline & 0.247 & 0.103 & 0.483 & 0.037 & & & \\
\hline & & & & & -1.00 & -0.50 & 1.00 \\
\hline
\end{tabular}

Supplementary Figure 4 Forest plot, high-grade dysplasia / intramucosal carcinoma 


\begin{tabular}{|c|c|c|c|c|c|c|c|c|}
\hline \multirow[t]{2}{*}{ Study name } & \multicolumn{3}{|c|}{ Statistics for each study } & & & \multicolumn{3}{|c|}{ Event rate and $95 \% \mathrm{Cl}$} \\
\hline & $\begin{array}{r}\text { Event } \\
\text { rate }\end{array}$ & $\begin{array}{r}\text { Lower } \\
\text { limit }\end{array}$ & $\begin{array}{r}\text { Upper } \\
\text { limit }\end{array}$ & p-Value & & & & \\
\hline Yamasaki, 2018 & 0.033 & 0.005 & 0.202 & 0.001 & & & & \\
\hline Binmoeller, 2013 & 0.333 & 0.131 & 0.624 & 0.258 & & & & \\
\hline Shibuwaka, 2018 & 0.071 & 0.010 & 0.370 & 0.013 & & & & \\
\hline Flynn, 2014 & 0.167 & 0.010 & 0.806 & 0.299 & & & & \\
\hline Doyama, 2018 & 0.022 & 0.001 & 0.268 & 0.008 & & & & \\
\hline Comella, 2017 & 0.182 & 0.046 & 0.507 & 0.054 & & & & \\
\hline Kiguchi, 2019 & 0.022 & 0.006 & 0.085 & 0.000 & & & & \\
\hline \multirow[t]{3}{*}{ Takahashi, 2018} & 0.009 & 0.001 & 0.123 & 0.001 & & & & \\
\hline & 0.069 & 0.025 & 0.179 & 0.000 & & & & \\
\hline & & & & & -1.00 & -0.50 & 0.00 & 1.00 \\
\hline
\end{tabular}

Supplementary Figure 5 Forest plot, adverse events

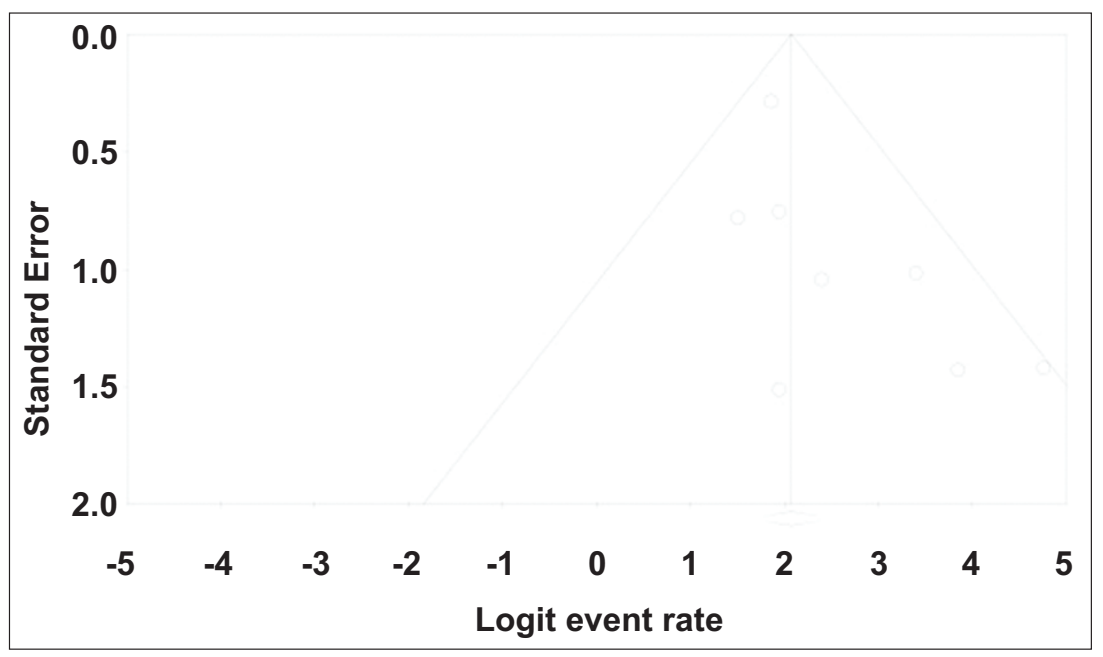

Supplementary Figure 6 Funnel plot 


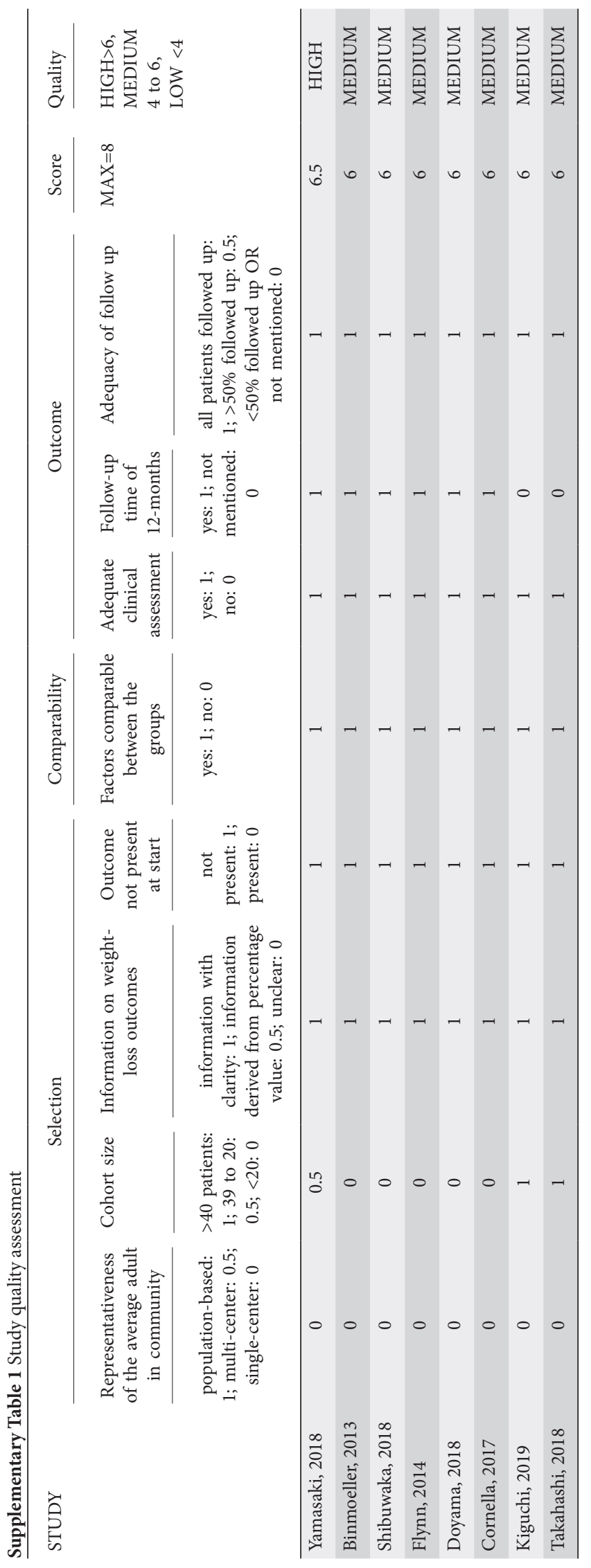




\section{APPENDIX 1}

Literature search strategy:

\section{Strategy:}

PubMed (15)

((Underwater AND endoscop*) OR “UW-EMR” OR UEMR) AND (duodenum OR duodenal) Limit to English

Embase (26)

(underwater AND endoscop* OR “UW-EMR” OR uemr) AND ('duodenum’/exp OR duodenum OR duodena*)AND [english]/lim

Scopus (16)

(TITLE-ABS-KEY ((underwater AND endoscop*) OR “UW-EMR” OR uemr) AND TITLE-ABS-KEY (duoden*))

\section{APPENDIX 2}

\begin{tabular}{|c|c|c|c|}
\hline Section/topic & \# & Checklist item & Reported on page \# \\
\hline \multicolumn{4}{|l|}{ TITLE } \\
\hline Title & 1 & Identify the report as a systematic review, meta-analysis, or both. & 1 \\
\hline \multicolumn{4}{|l|}{ ABSTRACT } \\
\hline Structured summary & 2 & $\begin{array}{l}\text { Provide a structured summary including, as applicable: background; objectives; } \\
\text { data sources; study eligibility criteria, participants, and interventions; study } \\
\text { appraisal and synthesis methods; results; limitations; conclusions and implications } \\
\text { of key findings; systematic review registration number. }\end{array}$ & $2-3$ \\
\hline \multicolumn{4}{|l|}{ INTRODUCTION } \\
\hline Rationale & 3 & Describe the rationale for the review in the context of what is already known. & $3-4$ \\
\hline Objectives & 4 & $\begin{array}{l}\text { Provide an explicit statement of questions being addressed with reference to } \\
\text { participants, interventions, comparisons, outcomes, and study design (PICOS). }\end{array}$ & $3-4$ \\
\hline \multicolumn{4}{|l|}{ METHODS } \\
\hline $\begin{array}{l}\text { Protocol and } \\
\text { registration }\end{array}$ & 5 & $\begin{array}{l}\text { Indicate if a review protocol exists, if and where it can be accessed (e.g., Web } \\
\text { address), and, if available, provide registration information including registration } \\
\text { number. }\end{array}$ & -na- \\
\hline Eligibility criteria & 6 & $\begin{array}{l}\text { Specify study characteristics (e.g., PICOS, length of follow up) and report } \\
\text { characteristics (e.g., years considered, language, publication status) used as criteria } \\
\text { for eligibility, giving rationale. }\end{array}$ & 4 \\
\hline Information sources & 7 & $\begin{array}{l}\text { Describe all information sources (e.g., databases with dates of coverage, contact } \\
\text { with study authors to identify additional studies) in the search and date last } \\
\text { searched. }\end{array}$ & 4 \\
\hline Search & 8 & $\begin{array}{l}\text { Present full electronic search strategy for at least one database, including any limits } \\
\text { used, such that it could be repeated. }\end{array}$ & 4 \\
\hline Study selection & 9 & $\begin{array}{l}\text { State the process for selecting studies (i.e., screening, eligibility, included in } \\
\text { systematic review, and, if applicable, included in the meta-analysis). }\end{array}$ & 4 \\
\hline Data collection process & 10 & $\begin{array}{l}\text { Describe method of data extraction from reports (e.g., piloted forms, } \\
\text { independently, in duplicate) and any processes for obtaining and confirming data } \\
\text { from investigators. }\end{array}$ & $4-5$ \\
\hline Data items & 11 & $\begin{array}{l}\text { List and define all variables for which data were sought (e.g., PICOS, funding } \\
\text { sources) and any assumptions and simplifications made. }\end{array}$ & $4-5$ \\
\hline $\begin{array}{l}\text { Risk of bias in } \\
\text { individual studies }\end{array}$ & 12 & $\begin{array}{l}\text { Describe methods used for assessing risk of bias of individual studies (including } \\
\text { specification of whether this was done at the study or outcome level), and how this } \\
\text { information is to be used in any data synthesis. }\end{array}$ & 5 \\
\hline
\end{tabular}




\begin{tabular}{|c|c|c|c|}
\hline Summary measures & 13 & State the principal summary measures (e.g., risk ratio, difference in means). & $5-6$ \\
\hline Synthesis of results & 14 & $\begin{array}{l}\text { Describe the methods of handling data and combining results of studies, if done, } \\
\left.\text { including measures of consistency (e.g., } I^{2}\right) \text { for each meta-analysis. }\end{array}$ & 6 \\
\hline $\begin{array}{l}\text { Risk of bias across } \\
\text { studies }\end{array}$ & 15 & $\begin{array}{l}\text { Specify any assessment of risk of bias that may affect the cumulative evidence (e.g., } \\
\text { publication bias, selective reporting within studies). }\end{array}$ & $5-6$ \\
\hline Additional analyses & 16 & $\begin{array}{l}\text { Describe methods of additional analyses (e.g., sensitivity or subgroup analyses, } \\
\text { meta-regression), if done, indicating which were pre-specified. }\end{array}$ & $5-6$ \\
\hline \multicolumn{4}{|l|}{ RESULTS } \\
\hline Study selection & 17 & $\begin{array}{l}\text { Give numbers of studies screened, assessed for eligibility, and included in the } \\
\text { review, with reasons for exclusions at each stage, ideally with a flow diagram. }\end{array}$ & 6 \\
\hline Study characteristics & 18 & $\begin{array}{l}\text { For each study, present characteristics for which data were extracted (e.g., study } \\
\text { size, PICOS, follow-up period) and provide the citations. }\end{array}$ & 6 \\
\hline $\begin{array}{l}\text { Risk of bias within } \\
\text { studies }\end{array}$ & 19 & $\begin{array}{l}\text { Present data on risk of bias of each study and, if available, any outcome level } \\
\text { assessment (see item 12). }\end{array}$ & 7 \\
\hline $\begin{array}{l}\text { Results of individual } \\
\text { studies }\end{array}$ & 20 & $\begin{array}{l}\text { For all outcomes considered (benefits or harms), present, for each study: (a) simple } \\
\text { summary data for each intervention group (b) effect estimates and confidence } \\
\text { intervals, ideally with a forest plot. }\end{array}$ & 7 \\
\hline Synthesis of results & 21 & $\begin{array}{l}\text { Present the main results of the review. If meta-analyses are done, include for each, } \\
\text { confidence intervals and measures of consistency }\end{array}$ & 6 \\
\hline $\begin{array}{l}\text { Risk of bias across } \\
\text { studies }\end{array}$ & 22 & Present results of any assessment of risk of bias across studies (see Item 15). & 7 \\
\hline Additional analysis & 23 & $\begin{array}{l}\text { Give results of additional analyses, if done (e.g., sensitivity or subgroup analyses, } \\
\text { meta-regression [see Item 16]). }\end{array}$ & $6-7$ \\
\hline \multicolumn{4}{|l|}{ DISCUSSION } \\
\hline Summary of evidence & 24 & $\begin{array}{l}\text { Summarize the main findings including the strength of evidence for each main } \\
\text { outcome; consider their relevance to key groups (e.g., healthcare providers, users, } \\
\text { and policy makers). }\end{array}$ & $7-9$ \\
\hline Limitations & 25 & $\begin{array}{l}\text { Discuss limitations at study and outcome level (e.g., risk of bias), and at review- } \\
\text { level (e.g., incomplete retrieval of identified research, reporting bias). }\end{array}$ & $7-9$ \\
\hline Conclusions & 26 & $\begin{array}{l}\text { Provide a general interpretation of the results in the context of other evidence, and } \\
\text { implications for future research. }\end{array}$ & $7-9$ \\
\hline \multicolumn{4}{|l|}{ FUNDING } \\
\hline Funding & 27 & $\begin{array}{l}\text { Describe sources of funding for the systematic review and other support (e.g., } \\
\text { supply of data); role of funders for the systematic review. }\end{array}$ & 1 \\
\hline
\end{tabular}

From: Moher D, Liberati A, Tetzlaff J, Altman DG, The PRISMA Group. Preferred Reporting Items for Systematic Reviews and Meta-Analyses: The PRISMA Statement. PLoS Med 2009;6:e1000097 
APPENDIX 3 MOOSE Checklist for meta-analyses of observational studies

\begin{tabular}{|c|c|c|}
\hline Item No & Recommendation & Reported on Page No \\
\hline \multicolumn{3}{|c|}{ Reporting of background should include } \\
\hline 1 & Problem definition & $3-4$ \\
\hline 2 & Hypothesis statement & - \\
\hline 3 & Description of study outcome(s) & $4-5$ \\
\hline 4 & Type of exposure or intervention used & $4-5$ \\
\hline 5 & Type of study designs used & $4-5$ \\
\hline 6 & Study population & 4 \\
\hline \multicolumn{3}{|c|}{ Reporting of search strategy should include } \\
\hline 7 & Qualifications of searchers (e.g., librarians and investigators) & 4, appendix 1 \\
\hline 8 & Search strategy, including time period included in the synthesis and key words & 4, appendix 1 \\
\hline 9 & Effort to include all available studies, including contact with authors & 4 \\
\hline 10 & Databases and registries searched & 4, appendix 1 \\
\hline 11 & Search software used, name and version, including special features used (e.g., explosion) & Appendix 1 \\
\hline 12 & Use of hand searching (e.g., reference lists of obtained articles) & - na- \\
\hline 13 & List of citations located and those excluded, including justification & Appendix 1 \\
\hline 14 & Method of addressing articles published in languages other than English & - na- \\
\hline 15 & Method of handling abstracts and unpublished studies & 4 \\
\hline 16 & Description of any contact with authors & - na- \\
\hline \multicolumn{3}{|c|}{ Reporting of methods should include } \\
\hline 17 & $\begin{array}{l}\text { Description of relevance or appropriateness of studies assembled for assessing the hypothesis } \\
\text { to be tested }\end{array}$ & 4 \\
\hline 18 & Rationale for the selection and coding of data (e.g., sound clinical principles or convenience) & 4 \\
\hline 19 & $\begin{array}{l}\text { Documentation of how data were classified and coded (e.g., multiple raters, blinding and } \\
\text { interrater reliability) }\end{array}$ & 4 \\
\hline 20 & Assessment of confounding (e.g., comparability of cases and controls in studies where appropriate) & 4 \\
\hline 21 & $\begin{array}{l}\text { Assessment of study quality, including blinding of quality assessors, stratification or regression } \\
\text { on possible predictors of study results }\end{array}$ & 7 \\
\hline 22 & Assessment of heterogeneity & 7 \\
\hline 23 & $\begin{array}{l}\text { Description of statistical methods (e.g., complete description of fixed or random effects } \\
\text { models, justification of whether the chosen models account for predictors of study results, } \\
\text { dose-response models, or cumulative meta-analysis) in sufficient detail to be replicated }\end{array}$ & 5 \\
\hline 24 & Provision of appropriate tables and graphics & Table1, supplementary materials \\
\hline \multicolumn{3}{|c|}{ Reporting of results should include } \\
\hline 25 & Graphic summarizing individual study estimates and overall estimate & Supplementary materials \\
\hline 26 & Table giving descriptive information for each study included & Supplementary Table 1 \\
\hline 27 & Results of sensitivity testing (e.g., subgroup analysis) & $6-7$ \\
\hline 28 & Indication of statistical uncertainty of findings & 5 \\
\hline \multicolumn{3}{|c|}{ Reporting of discussion should include } \\
\hline 29 & Quantitative assessment of bias (e.g., publication bias) & 7 \\
\hline 30 & Justification for exclusion (e.g., exclusion of non-English language citations) & -na- \\
\hline 31 & Assessment of quality of included studies & 7, Supplementary Table 1 \\
\hline \multicolumn{3}{|c|}{ Reporting of conclusions should include } \\
\hline 32 & Consideration of alternative explanations for observed results & $7-9$ \\
\hline 33 & $\begin{array}{l}\text { Generalization of the conclusions (i.e., appropriate for the data presented and within the } \\
\text { domain of the literature review) }\end{array}$ & $7-9$ \\
\hline 34 & Guidelines for future research & $8-9$ \\
\hline 35 & Disclosure of funding source & 1 \\
\hline
\end{tabular}

From: Stroup DF, Berlin JA, Morton SC, et al, for the Meta-analysis Of Observational Studies in Epidemiology (MOOSE) Group. Meta-analysis of Observational Studies in Epidemiology. A Proposal for Reporting. JAMA 2000;283:2008-2012 